\title{
Percentage of current tobacco smoking students receiving help or advice to quit: Evidence from the Global Youth Tobacco Survey, 56 countries, 2012-2015
}

\author{
René A. Arrazola ${ }^{1}$ Andrew B. Seidenberg ${ }^{2}$, Indu B. Ahluwalia ${ }^{1}$
}

\begin{abstract}
INTRODUCTION We assessed self-reported receipt of help or advice to stop smoking among current tobacco smoking students enrolled in school.

METHODS Using cross-sectional data collected between 2012-2015 from the Global Youth Tobacco Survey (GYTS), and representing the latest year for which data were collected, we calculated prevalence of receipt of help or advice to stop smoking among current tobacco smoking students aged 13-15 years from 56 countries. The sources of help or advice assessed in the GYTS were: 1) from a program or professional, 2) from a friend, and 3) from a family member. Overall response rates ranged from $60.3 \%$ in Nicaragua to $99.2 \%$ in Sudan. The analytic sample size ranged from 55 in Gabon to 950 in Bulgaria.

RESULTS In 53 of the 56 assessed countries, more than half of current tobacco smoking students received help or advice to quit from either a program or professional, friend, or family member (range $=39.9 \%$ San Marino to $96.9 \%$ Timor-Leste). From a friend or family member only, the range was $37.2 \%$ Bahamas to $69.9 \%$ Montenegro, and from a program or professional only, the range was 3.7\% Latvia to $34.2 \%$ Togo.

CONCLUSIONS Family and friends are the most common sources of help or advice to quit smoking among current tobacco smoking students in the GYTS countries assessed, while programs and professionals were the least common. The use of evidence-based measures is critical to prevent and reduce tobacco use among youth and to ensure they are receiving appropriate help or advice to quit.
\end{abstract}

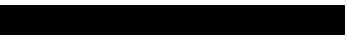

AFFILIATION

1 Office on Smoking and Health, National Center for Chronic Disease Prevention and Health Promotion, Atlanta, United States

2 Department of Health Behavior, Gillings School of Global Public Health, University of North Carolina at Chapel Hill, Chapel Hill, United States

CORRESPONDENCE TO René A. Arrazola. Office on Smoking and Health, National Center for Chronic Disease Prevention and Health Promotion, Centers for Disease Control and Prevention, Atlanta, GA, United States. Email: fdy9@cdc.gov

\section{KEYWORDS}

students, quitting tobacco smoking, help, advice, Global Youth Tobacco Survey
\end{abstract}

Received: 26 September 2018 Revised: 14 December 2018 Accepted: 17 January 2019

\section{INTRODUCTION}

Tobacco use contributes to 6.4 million deaths globally each year ${ }^{1}$ and most tobacco smokers begin smoking during adolescence ${ }^{2}$. Smoking during adolescence causes health problems, such as increased number and severity of respiratory illness, and lifelong smoking also causes cancer and cardiovascular disease $^{3}$. Therefore, preventing tobacco use among youth is a critical strategy to reduce overall tobacco use $^{2,4}$. Adolescence may represent an opportune time for tobacco cessation with the goal of preventing more established or long-term tobacco use ${ }^{3}$. A recent report found that, in 40 of 51 countries, $>50 \%$ of current tobacco smoking students aged 13-15 years want to quit ${ }^{5}$. Helping or advising youth tobacco smokers to quit smoking may lead to increased quit attempts, reduced likelihood of lifelong tobacco use, and reductions in morbidity and mortality.

This brief report describes self-reported receipt of help or advice to stop smoking among current tobacco smoking youth aged 13-15 years enrolled in school from 56 countries, chosen by criteria specified below. 


\section{METHODS}

\section{Data}

Data came from the Global Youth Tobacco Survey (GYTS), a nationally representative school-based, paper and pencil, cross-sectional survey of students in school grades associated with ages $13-15$ years. Classes within selected schools are randomly selected and all students in selected classes are eligible to participate in the survey. The GYTS uses a two-stage cluster sample design with schools selected at the first stage with probability proportional to the enrollment size followed by classes chosen randomly within selected schools. The data were weighted to reflect country specific prevalence estimates and were adjusted for school and class clustering as well as for non-response and post-stratification relative to grade and $\operatorname{sex}^{6}$. For this report, countries were included if they met the following criteria: 1) nationally representative data were available for students aged 13-15 years; 2 ) latest year for which data were collected and available was within the period 2012-2015, to allow calculation of recent prevalence estimates; and 3) unweighted sample size, for number of current tobacco smokers with non-missing responses to the item asking about ever receiving help or advice to stop smoking, was $\geq 35$. Based on these criteria, 56 countries were selected for analyses. Overall response rates ranged from $60.3 \%$ in Nicaragua to $99.2 \%$ in Sudan. The analytic sample size ranged from 55 in Gabon to 950 in Bulgaria.

\section{Measures}

Consistent with the existing literature, current tobacco smoking among students aged 13-15 years, was defined as having smoked a cigarette or other smoked tobacco product in the past 30 days $^{2}$. Current tobacco smoking students responded to an item asking: 'Have you ever received help or advice to help you stop smoking?'. Respondents could only choose from the following sources of support: 1 ) from a program or professional, 2) from a friend, 3) from a family member, or 4) from both programs or professionals and friend or family member. A response option of 'No', indicating that the student had not received advice to quit smoking, was also included. All responses are mutually exclusive. Responses for friend and family members were combined into a single answer choice. In addition, we created a composite variable for receiving any advice or help that combined professional/program and friend/ family member. Students who reported no current tobacco smoking were excluded.

\section{Analysis}

To account for the complex sampling procedures of GYTS, STATA (C) 14.2 software was used to generate country-specific weighted prevalence estimates and 95\% confidence intervals for receiving help or advice to stop smoking among student tobacco smokers. Estimates with a relative standard error $>0.3$ are not reported.

\section{RESULTS}

In 53 of 56 countries, the estimated point prevalence of reporting receiving any help or advice to quit smoking was $>50 \%$. Across all countries, the median estimated prevalence of receiving any help or advice to quit smoking among students aged $13-15$ years was $72.7 \%$ (range $=39.9 \%$ San Marino to $96.9 \%$ TimorLeste). The median estimated prevalences of help or advice to quit smoking were: 1 ) $52.5 \%$ (range $=37.2 \%$ Bahamas to $69.9 \%$ Montenegro) from a friend or family member only, 2) $8.8 \%$ (range=3.7\% Latvia to $34.2 \%$ Togo) from a professional or program only, and 3) $9.9 \%$ (range $=2.9 \%$ Romania to $31.4 \%$ Kenya) from both (Table 1).

Table 1. Prevalence of receiving advice or help to stop smoking among current tobacco smoking students aged 13-15 years, in 56 countries, Global Youth Tobacco Survey, 2012-2015

\begin{tabular}{|c|c|c|c|c|c|c|}
\hline WIIO Region Country & $\begin{array}{c}\text { Overall } \\
\text { sample size } \\
\text { (unweighted) }\end{array}$ & $\begin{array}{l}\text { Number } \\
\text { of current } \\
\text { tobaceo } \\
\text { smokers } \\
\text { (unweighted) }\end{array}$ & $\begin{array}{l}\text { Any advice } \\
\text { (weighted) }\end{array}$ & $\begin{array}{c}\text { Advice from } \\
\text { friend family } \\
\text { only } \\
\text { (weighted) }\end{array}$ & $\begin{array}{l}\text { Advice from } \\
\text { program } \\
\text { professional } \\
\text { only } \\
\text { (weighted) }\end{array}$ & $\begin{array}{l}\text { Advice from } \\
\text { both friend } \\
\text { family and } \\
\text { program } \\
\text { professional } \\
\text { (weighted) }\end{array}$ \\
\hline & & & $\%\left(95^{\circ} \%\left(\mathrm{I}^{\mathrm{a}}\right)\right.$ & $\%\left(95^{\circ} \% \mathrm{CI}\right)$ & $\%(95 \% \mathrm{CI})$ & $\%\left(95^{\circ} \% \mathrm{CI}\right)$ \\
\hline
\end{tabular}


Table 1. Continued

\begin{tabular}{|c|c|c|c|c|c|c|}
\hline WIIO Region Country & $\begin{array}{c}\text { Overall } \\
\text { sample sive } \\
\text { (unweighted) }\end{array}$ & $\begin{array}{l}\text { Number } \\
\text { of current } \\
\text { tobaceo } \\
\text { smokers } \\
\text { (unweighted) }\end{array}$ & $\begin{array}{l}\text { Any advice } \\
\text { (weighted) }\end{array}$ & $\begin{array}{l}\text { Advice from } \\
\text { friend family } \\
\text { only } \\
\text { (weighted) }\end{array}$ & $\begin{array}{l}\text { Advice from } \\
\text { program } \\
\text { professional } \\
\text { only } \\
\text { (weighted) }\end{array}$ & $\begin{array}{l}\text { Advice from } \\
\text { both friend } \\
\text { family and } \\
\text { program } \\
\text { professional } \\
\text { (weighted) }\end{array}$ \\
\hline & & & $\%\left(95^{\circ} \% C 1^{a}\right)$ & $\%\left(95^{\circ} \% \mathrm{CI}\right)$ & $\%\left(95^{\circ} \% \mathrm{CI}\right)$ & $\%\left(95^{\circ} \% \mathrm{CI}\right)$ \\
\hline Cameroon (2014) & 1873 & 136 & $71.5(56.4,83.0)$ & $56.0(43.0,68.2)$ & $8.3(4.4,15.1)$ & $-{ }^{b}$ \\
\hline Comoros (2015) & 1551 & 127 & $81.8(61.1,92.8)$ & $44.6(30.7,59.5)$ & $29.5(20.7,40.1)$ & - \\
\hline Gabon (2014) & 788 & 55 & $72.7(61.2,81.8)$ & $47.5(27.1,68.8)$ & $19.7(11.8,31.1)$ & - \\
\hline Kenya (2013) & 1326 & 84 & $83.4(69.8,91.6)$ & $45.6(35.0,56.7)$ & - & $31.4(21.0,44.0)$ \\
\hline Mozambique (2013) & 3062 & 158 & $82.8(67.6,91.7)$ & $61.0(46.4,73.9)$ & - & - \\
\hline Seychelles (2015) & 1525 & 278 & $71.4(65.0,77.1)$ & $54.2(48.3,59.9)$ & $8.2(5.3,12.5)$ & $9.0(5.3,14.8)$ \\
\hline Togo (2013) & 2801 & 182 & $90.4(83.5,94.5)$ & $52.2(43.1,61.2)$ & $34.2(25.8,43.8)$ & - \\
\hline Zimbabwe (2014) & 5114 & 530 & $81.7(65.3,91.4)$ & $59.5(40.8,75.7)$ & $14.5(7.9,25.1)$ & $7.7(4.5,12.9)$ \\
\hline \multicolumn{7}{|l|}{ Eastern Mediterranean Region } \\
\hline Bahrain (2015) & 2465 & 305 & $86.1(78.0,91.5)$ & $59.6(51.6,67.2)$ & $11.2(6.4,18.8)$ & $15.2(10.8,21.0)$ \\
\hline Djibouti (2013) & 1361 & 130 & $64.4(47.4,78.4)$ & $43.3(30.3,57.3)$ & $16.4(9.5,26.9)$ & - \\
\hline Egypt (2014) & 2141 & 202 & $88.1(78.2,93.9)$ & $62.3(40.5,80.1)$ & - & - \\
\hline Iraq (2014) & 1266 & 139 & $87.5(79.0,92.8)$ & $64.4(56.7,71.4)$ & $18.9(12.0,28.6)$ & - \\
\hline Jordan (2014) & 1889 & 416 & $73.8(66.6,79.9)$ & $55.3(48.0,62.3)$ & $8.9(5.5,14.1)$ & $9.5(6.2,14.3)$ \\
\hline Pakistan (2013) & 5832 & 334 & $77.4(65.1,86.3)$ & $54.7(44.2,64.8)$ & - & $7.0(4.3,11.2)$ \\
\hline Qatar (2013) & 1716 & 202 & $75.8(69.3,81.4)$ & $50.1(39.9,60.2)$ & $11.4(7.3,17.5)$ & $14.3(10.4,19.5)$ \\
\hline Sudan (2014) & 1450 & 105 & $86.8(72.7,94.2)$ & $48.5(36.3,60.9)$ & $31.7(21.8,43.7)$ & - \\
\hline United Arab Emirates (2013) & 3376 & 320 & $71.2(64.2,77.4)$ & $50.5(43.5,57.4)$ & $7.4(4.2,12.5)$ & $13.3(9.1,19.2)$ \\
\hline Yemen (2014) & 1634 & 212 & $82.1(72.5,88.8)$ & $60.0(50.0,69.2)$ & $14.1(7.6,24.7)$ & - \\
\hline \multicolumn{7}{|l|}{ European Region } \\
\hline Albania (2015) & 3482 & 319 & $65.4(57.5,72.5)$ & $47.4(38.6,56.4)$ & $8.3(5.0,13.4)$ & $9.7(6.3,14.5)$ \\
\hline Belarus (2015) & 2428 & 213 & $67.6(58.2,75.8)$ & $47.4(39.0,56.0)$ & $10.0(5.7,17.0)$ & - \\
\hline Bulgaria (2015) & 3532 & 950 & $65.1(59.2,70.5)$ & $53.1(47.8,58.2)$ & $5.1(3.0,8.4)$ & $7.0(5.0,9.5)$ \\
\hline Georgia (2014) & 962 & 86 & $72.9(61.8,81.7)$ & $58.8(47.9,68.9)$ & - & - \\
\hline Greece (2013) & 4096 & 535 & $58.8(53.8,63.6)$ & $46.0(40.6,51.6)$ & - & $9.9(6.6,14.5)$ \\
\hline Italy (2014) & 1428 & 313 & $47.6(41.2,54.0)$ & $40.1(34.3,46.2)$ & - & $6.5(4.3,9.8)$ \\
\hline Kyrgyzstan (2014) & 3468 & 170 & $70.3(57.9,80.4)$ & $46.2(35.6,57.3)$ & - & - \\
\hline Latvia (2014) & 4025 & 861 & $50.9(44.0,57.9)$ & $41.7(35.8,48.0)$ & $3.7(2.1,6.5)$ & $5.5(3.7,8.0)$ \\
\hline Lithuania (2014) & 3113 & 736 & $57.7(52.0,63.2)$ & $39.5(35.3,43.8)$ & $8.4(6.1,11.4)$ & $9.8(7.3,13.1)$ \\
\hline Moldova (2013) & 3548 & 285 & $77.6(71.0,83.1)$ & $60.7(53.4,67.6)$ & - & $11.4(7.6,16.8)$ \\
\hline Montenegro (2014) & 3692 & 342 & $75.9(52.2,90.1)$ & $69.9(43.6,87.5)$ & - & - \\
\hline Portugal (2013) & 7600 & 902 & $59.9(55.0,64.5)$ & $44.7(40.1,49.3)$ & $4.9(2.8,8.7)$ & $10.3(7.0,14.7)$ \\
\hline Romania (2013) & 3328 & 348 & $59.1(52.1,65.7)$ & $47.6(40.5,54.8)$ & $8.5(5.0,14.3)$ & $2.9(1.7,5.0)$ \\
\hline San Marino (2014) & 534 & 77 & $39.9(28.0,53.1)$ & $38.1(26.4,51.3)$ & - & - \\
\hline Serbia (2013) & 3076 & 460 & $63.3(57.7,68.7)$ & $55.7(50.1,61.2)$ & $4.1(2.2,7.3)$ & - \\
\hline \multicolumn{7}{|l|}{ Region of the Americas } \\
\hline Argentina (2012) & 2069 & 355 & $65.5(58.1,72.2)$ & $57.6(5.0,64.9)$ & $4.6(2.8,7.6)$ & - \\
\hline Bahamas (2013) & 1033 & 108 & $54.0(39.3,68.1)$ & $37.2(26.7,49.1)$ & $7.1(2.7,17.2)$ & $9.7(3.8,22.8)$ \\
\hline Barbados (2013) & 1306 & 155 & $50.1(41.6,58.6)$ & $37.7(28.8,47.6)$ & - & - \\
\hline
\end{tabular}


Table 1. Continued

\begin{tabular}{|c|c|c|c|c|c|c|}
\hline \multirow[t]{2}{*}{ WIIO Region Country } & \multirow[t]{2}{*}{$\begin{array}{c}\text { Overall } \\
\text { sample sive } \\
\text { (unweighted) }\end{array}$} & \multirow[t]{2}{*}{$\begin{array}{l}\text { Number } \\
\text { of current } \\
\text { tobaceo } \\
\text { smokers } \\
\text { (unweighted) }\end{array}$} & $\begin{array}{l}\text { Any advice } \\
\text { (weighted) }\end{array}$ & $\begin{array}{l}\text { Advice from } \\
\text { friend family } \\
\text { only } \\
\text { (weighted) }\end{array}$ & \multirow[t]{2}{*}{$\begin{array}{c}\text { Advice from } \\
\text { program } \\
\text { professional } \\
\text { only } \\
\text { (weighted) } \\
\%(95 \% \mathrm{CI})\end{array}$} & \multirow[t]{2}{*}{$\begin{array}{l}\text { Advice from } \\
\text { both friend } \\
\text { family and } \\
\text { program } \\
\text { professional } \\
\text { (weighted) } \\
\%(95 \% \text { CI) }\end{array}$} \\
\hline & & & $\%\left(95^{\circ} \% C \mathrm{Cl}^{\mathrm{a}}\right)$ & $\%(95 \%$ CI $)$ & & \\
\hline Belize (2014) & 1273 & 131 & $70.9(58.4,80.9)$ & $52.1(42.8,61.4)$ & - & $9.8(5.9,15.8)$ \\
\hline Costa Rica (2013) & 2158 & 171 & $46.0(38.8,53.4)$ & $37.9(30.2,46.3)$ & - & - \\
\hline El Salvador (2015) & 2567 & 302 & $78.9(72.9,83.8)$ & $59.0(53.0,64.8)$ & $8.8(5.4,14.2)$ & $11.0(8.1,14.8)$ \\
\hline Guatemala (2015) & 3351 & 479 & $59.7(53.2,65.8)$ & $48.0(41.5,54.6)$ & $7.7(4.4,13.1)$ & $4.0(2.6,6.1)$ \\
\hline Guyana (2015) & 1000 & 105 & $83.2(74.8,89.2)$ & $52.8(40.6,64.7)$ & - & $11.8(6.8,19.7)$ \\
\hline Nicaragua (2014) & 3006 & 394 & $78.7(71.7,84.4)$ & $61.5(54.0,68.5)$ & $9.9(6.1,15.5)$ & $7.4(5.1,10.4)$ \\
\hline Panama (2012) & 4077 & 316 & $72.2(64.7,78.6)$ & $52.7(43.9,61.3)$ & $9.2(4.5,17.8)$ & $10.4(6.4,16.3)$ \\
\hline Paraguay (2014) & 5153 & 331 & $57.2(44.1,69.4)$ & $44.9(32.2,58.3)$ & - & - \\
\hline Peru (2014) & 2299 & 229 & $68.7(46.1,84.9)$ & $46.4(31.8,61.6)$ & - & $13.9(7.6,23.9)$ \\
\hline Uruguay (2014) & 3256 & 312 & $72.6(65.4,78.8)$ & $54.8(47.9,61.5)$ & $8.1(5.1,12.6)$ & $9.7(6.5,14.3)$ \\
\hline \multicolumn{7}{|l|}{ South-East Asian Region } \\
\hline Bhutan (2013) & 1378 & 206 & $89.1(82.5,93.3)$ & $63.7(57.6,69.5)$ & - & $19.1(13.8,25.9)$ \\
\hline Indonesia (2014) & 4317 & 691 & $90.7(88.0,92.7)$ & $67.3(61.8,72.4)$ & $5.6(4.2,7.5)$ & $17.7(13.5,23.0)$ \\
\hline Thailand (2015) & 1721 & 218 & $83.3(76.0,88.7)$ & $54.0(47.0,60.7)$ & $15.7(10.2,23.3)$ & $13.6(8.7,20.8)$ \\
\hline Timor-Leste (2013) & 1908 & 529 & $96.9(94.7,98.2)$ & $65.4(54.3,75.0)$ & $14.0(8.9,21.3)$ & $17.5(9.9,29.0)$ \\
\hline \multicolumn{7}{|l|}{ Western Pacific Region } \\
\hline Brunei Darussalam (2013) & 917 & 80 & $81.9(67.7,90.8)$ & $49.0(35.2,63.0)$ & - & - \\
\hline Mongolia (2014) & 6178 & 399 & $58.5(51.8,65.0)$ & $46.0(39.1,53.1)$ & - & $7.3(4.7,11.3)$ \\
\hline Philippines (2015) & 5885 & 711 & $86.6(81.8,90.3)$ & $52.9(45.8,59.9)$ & $21.1(11.9,34.6)$ & $12.6(9.4,16.8)$ \\
\hline South Korea (2013) & 3437 & 186 & $63.0(55.6,69.8)$ & $45.1(39.5,50.8)$ & $8.8(5.1,14.6)$ & $9.1(5.1,15.8)$ \\
\hline Vietnam (2014) & 3430 & 110 & $88.1(79.0,93.6)$ & $61.0(47.5,73.0)$ & - & - \\
\hline MEDIAN & 2516 & 281.5 & $72.7(69.2,76.1)$ & $52.5(50.3,54.6)$ & $8.8(6.3,11.3)$ & $9.9(8.1,11.6)$ \\
\hline
\end{tabular}

a 95\% Confidence Interval. b Data not reported due to relative standard error $>0.3$.

\section{DISCUSSION}

Our research shows that in 53 out of 56 countries surveyed, more than half of current tobacco smoking students reported receiving some help or advice to quit. Tobacco smoking students' family and friends were the most common sources of help or advice to quit. In contrast, public health programs and health professionals were the least common sources. These data show that more than five out of ten current tobacco smoking students seek help or advice from only non-evidence based sources in 32 countries. These students may be receiving incorrect information about how to quit smoking tobacco, which may result in poorer cessation outcomes and longer-term tobacco smoking. These findings indicate that opportunities exist to enhance promotion of evidence-based tobacco prevention and control strategies, such as advice from health professionals, in addition to populationlevel education on the dangers of tobacco smoking among youth. While our study was unable to assess whether current tobacco smoking students received advice or help from other sources, such as social media and internet-based intervention, some of these interventions are discussed in the literature as potential ways to provide important services to students ${ }^{7.8}$. Important considerations are that any smoking cessation program/intervention needs to be age-appropriate and meet the needs of youth as well as being culturally appropriate. New technologies, such as mobile phones and social media platforms, 
could offer new opportunities to expand cessation services to youth, but these may not be feasible in low resource settings, which would include 40 low and middle income countries in this study at time of survey administration. Future research is needed at individual country levels to inform evidence-based leveraging of health communication related to tobacco prevention and cessation.

The World Health Organization (WHO) Framework Convention on Tobacco Control (FCTC) treaty, which, as of December 2017, 55 of 56 countries in this analysis have ratified, focuses on evidence-based measures that help keep people safe from tobacco ${ }^{9}$. Specific Articles outlined in FCTC include warning on the dangers of tobacco use (Article 12) and highlighting the benefits of tobacco cessation (Article 14) ${ }^{9}$. To help countries implement FCTC, WHO developed the MPOWER demand reduction strategies ${ }^{10}$; when these strategies are implemented as part of a comprehensive tobacco control approach, they can help prevent and reduce youth tobacco use $\mathrm{e}^{2,11,12}$. Additional components of a comprehensive approach can also include subnational efforts by health professionals and tobacco control programs. For example, health professionals could use the ' 5 As' method as a practical framework to identify and assist youth who smoke tobacco ${ }^{8}$. Trainings and tools for health professional, such as Treatment and Beyond ${ }^{13}$, are available in the Internet that may help increase their capacity to provide tobacco cessation advice and counseling, and enhance their knowledge and understanding of tobacco prevention and control strategies. Additionally, tobacco control programs could implement youth-oriented campaigns that warn about the dangers of tobacco smoking to help reduce youth smoking ${ }^{2,11}$.

\section{Limitations}

This report has some limitations. First, data were self-reported by students, which might result in misreporting of smoking behavior and/or receipt of help or advice to quit. Second, the data are from those who were enrolled in school, which limits generalizability to all youths. Third, low response rates in some countries, and the use of complete case analysis, might have resulted in non-response bias. Finally, GYTS only assesses receipt of help or advice to quit smoking from programs or professionals, from friends, and from family members, and does not assess use of social networks, social media, or internet access and use. These could potentially be important considerations for developing school-based cessation or other types of advice and cessation services for youth.

\section{CONCLUSIONS}

To our knowledge, this is the first study using GYTS data to assess current tobacco smoking students who reported receiving help or advice to stop smoking; previous findings revealed that many current tobacco smoking students report a desire to quit ${ }^{5}$. The desire to quit smoking among students presents potential opportunities to develop programs and cessation strategies that could assist students in stopping a behavior that has lifelong consequences to wellbeing and health. Implementing evidence-based strategies outlined in WHO MPOWER, as part of a comprehensive tobacco control approach, can help prevent and reduce tobacco use among youth ${ }^{10}$, and may help countries to move towards a tobacco-free generation.

\section{REFERENCES}

1. GBD 2015 Tobacco Collaborators. Smoking prevalence and attributable disease burden in 195 countries and territories, 1990-2015: a systematic analysis from the Global Burden of Disease Study 2015. Lancet. 2017;389(10082):18851906. doi:10.1016/S0140-6736(17)30819-X

2. US Department of Health and Human Services. Preventing tobacco use among youth and young adults: a report of the Surgeon General. https://www.surgeongeneral. gov/library/reports/preventing-youth-tobacco-use/fullreport.pdf. Accessed September 26, 2018.

3. Schauer GL, Agaku IT, King BA, Malarcher AM. Health care provider advice for adolescent tobacco use: results from the 2011 National Youth Tobacco Survey. Pediatrics. 2014;134(3):446-455. doi:10.1542/peds.2014-0458

4. Fiore MC, Jaén CR, Baker TB, et al. Treating Tobacco Use and Dependence: 2008 Update. Clinical Practice Guideline. Rockville: U.S. Department of Health and Human Services. Public Health Service; 2008.

5. Arrazola RA, Ahluwalia IB, Pun E, Garcia De Quevedo I, Babb S, Armour BS. Current Tobacco Smoking and Desire to Quit Smoking Among Students Aged 13-15 Years Global Youth Tobacco Survey, 61 Countries, 2012-2015. Morbidity Mortality Weekly Report. 2017;66(20):533537. doi:10.15585/mmwr.mm6620a3

6. Global Youth Tobacco Survey Collaborative Group. 
Global Youth Tobacco Survey (GYTS): Sample Design and Weights, Version 1.1. Atlanta: Centers for Disease Control and Prevention; 2014.

7. Harvey J, Chadi N, Canadian Paediatric Society, Adolescent Health Committee. Strategies to promote smoking cessation among adolescents. Paediatrics and Child Health. 2016;21(4):201-204. doi:10.1093/pch/21.4.201

8. Nădăşan V, Chirvăsuţă R, Ábrám Z, Mihăicuţă Ş. Types of interventions for smoking prevention and cessation in children and adolescents. Pneumologia. 2015;64(3):5862.

9. World Health Organization. WHO Framework Convention on Tobacco Control. http://www.who.int/ tobacco/framework/WHO_FCTC_english.pdf. Accessed September 26, 2018.

10. World Health Organization. WHO Report on the Global Tobacco Epidemic, 2008: the MPOWER package. http://www.who.int/tobacco/mpower/mpower_report_ full_2008.pdf. Accessed September 26, 2018.

11. US Department of Health and Human Services. The Health Consequences of Smoking-50 Years of Progress: A Report of the Surgeon General, Atlanta: US Department of Health and Human Services, CDC, National Center for Chronic Disease Prevention and Health Promotion; 2014.

12. Difranza JR. Which interventions against the sale of tobacco to minors can be expected to reduce smoking? Tobacco Control. 2012;21(4):436-442. doi:10.1136/tobaccocontrol-2011-050145

13. CDC - Laboratory Training Team. (n.d). Treatment \& Beyond. A tobacco control prevention training tool for health care providers around the globe. https:// www.train.org/cdctrain/course/1065883/. Accessed September 26, 2018.

ACKNOWLEDGEMENTS

We would like to thank Linda Anton, GYTS Collaborating Group, and World Health Organization Collaborators. The findings and conclusions in this report are those of the authors and do not necessarily represent the official position of the Centers for Disease Control and Prevention.

CONFLICTS OF INTEREST Authors have completed and submitted the ICMJE Form for Disclosure of Potential Conflicts of Interest and none was reported.

FUNDING

Andrew B. Seidenberg is supported by the University of North Carolina Lineberger Cancer Control Education Program (T32 CA057726).

PROVENANCE AND PEER REVIEW

Not commissioned; externally peer reviewed. 